\title{
The Number of Louse Eggs on Wild Japanese Macaques (Macaca fuscata) Varies with Age, but Not with Sex or Season
}

\author{
Naomi Ishii ${ }^{1}$ - Takuya Kato $^{1}$ - Taiki Uno ${ }^{1}$. \\ Ichirou Tanaka $^{2} \cdot$ Hiroshi Kajigaya ${ }^{1}$. \\ Shin-ichi Hayama ${ }^{1}$
}

Received: 12 November 2015 / Accepted: 8 September 2017 /Published online: 10 November 2017 (C) The Author(s) 2017. This article is an open access publication

\begin{abstract}
During grooming, primates remove harmful ectoparasites, such as ticks and lice, and there is direct evidence for a health benefit of tick removal. Grooming behaviors differ among primates with respect to age and sex. Moreover, the number of ectoparasite may exhibit seasonal variation. Therefore the number of ectoparasites on a host may vary with effects, host age and sex, and season. However, these effects have not been a focus of louse infestation studies of primates. Grooming in Japanese macaques is related to sex and age, with developmental changes in behavior corresponding to the timing of tooth eruption. Moreover, behavioral data for Japanese macaques suggest that lice load may differ with the season. Thus, we examined whether the number of louse eggs varies according to host macaque sex, age, and season, and whether it changes in response to tooth eruption. We counted unhatched and hatched eggs attached to the hair on six $1-\mathrm{cm}^{2}$ areas on the left wrist skin of culled macaques, using a stereoscopic microscope. We sampled five winter coats and three summer coats for each age class: infant, juvenile, adolescent, and adult. The number of unhatched and hatched eggs was related to age, but not to sex and season. There were significant differences in the number of unhatched eggs between infants and adults, juveniles and adults, and adolescents and adults. There were also significant differences in the number of hatched eggs between infants and adults, juveniles and adults, adolescents and adults. Tooth eruption did not influence the number of louse eggs.
\end{abstract}

Handling Editor: Joanna M. Setchell.

Naomi Ishii

icnom.141703@gmail.com

1 Nippon Veterinary and Life Science University, Musashino, Tokyo 180-8602, Japan

2 Yokkaichi University, Yokkaichi, Mie 512-8512, Japan 
These results suggest that researchers should consider the age of host animals when assessing the relationship between grooming and ectoparasites.

Keywords Ectoparasites $\cdot$ Grooming $\cdot$ Host age $\cdot$ Host sex $\cdot$ Seasonality

\section{Introduction}

Grooming is a major defense strategy against ectoparasites, and is performed by various species, including insects, fishes, birds, and mammals (Sparks 1967). For example, cleaning symbioses are particularly well documented in marine ecosystems (Cote 2000; Johnson et al. 2010). In insects, the Asian honey bee (Apis cerana) shows self-cleaning behavior when inoculated with mites (Varroa jacobsoni: Peng et al. 1987). Animals groom using various methods and body parts, including the mouth, finger, and beak, and researchers have suggested that ectoparasite removal during grooming has a direct effect on well-being in a variety of species, e.g., cats (Felis domestica: Eckstein and Hart 2000), antelopes (Hart 2000), meerkats (Suricata suricatta: Kutsukake and Clutton-Brock (2006), and fishes (Johnson et al. 2010).

Primates also remove harmful ectoparasites, such as ticks and lice, as well as louse eggs, during grooming, e.g., Japanese macaques (Macaca fuscata: Tanaka and Takefushi 1993), chimpanzees (Pan troglodytes: Zamma 2002b), and baboons (Papio cynocephalus: Akinyi et al. 2013). Ticks and lice transmit protozoa and bacteria, which cause serious infections, such as babesiosis (Kjemtrup and Conrad 2000; Ruebush et al. 1981), epidemic typhus (Blanc and Woodward 1945; Burgess 1995; Roux and Raoult 1999), trench fever (Roux and Raoult 1999), and relapsing fever (Burgess 1995; Durden 2001). Moreover, they suck the blood of host animals and cause anemia in humans (Guss et al. 2011; Speare et al. 2006) and a wide range of wild mammals (Durden 2001), including spider monkeys (Ateles: Ronald and Wagner 1973). In light of the negative health effects that result from tick and lice infestation, removal of ectoparasites by grooming may play a significant role in maintaining host health.

Female nonhuman primates groom more than males (Minami 1987; Mitchell and Tokunaga 1976). Differences in grooming may lead to differences in the number of ectoparasites and health. This hypothesis is supported in the case of ticks: baboons that receive more grooming have fewer ticks (Akinyi et al. 2013). The authors suggested that grooming protects baboons from the detrimental effects of ticks because individuals with more ticks suffer from health effects, such as skin wounds and low packed cell volume, an indicator of anemia. Allogrooming rates and the occurrence of lice and nits vary among groups of red howlers (Aloutta seniculus: Sánchez-Villagra et al. 1998), and studies of Japanese macaques have shown that grooming site preferences correlate with the distribution of louse eggs (Zamma 2002a) and that grooming may limit louse burden (Duboscq et al. 2016).

Sex-related differences in grooming appear during development (Minami 1987). Hair density also influences the number of louse eggs (Zamma 2002a) and decreases with age (Inagaki and Hamada 1985; Inagaki 1992). For example, age-related differences in behavior and hair length lead to differences in head lice in humans (Borges and Mendes 2002; Speare and Buettner 1999). Thus, differences in host age may also lead to differences in the number of ectoparasites in other primates. 
The number of ectoparasites may also exhibit seasonal variation. For example, seasonal fluctuations in hormones (Nozaki 1991) associated with seasonal breeding of the host animals may influence reproduction of Phthiraptera (Duboscq et al. 2016; Durden 2001; Foster 1969). However, no reports have evaluated seasonal changes in the number of ectoparasites of primates directly.

Grooming in Japanese macaques is closely connected to louse eggs. Almost all (98.9\%) of the objects that macaques pick up and then eat during grooming are louse eggs (Pedicinus obtusus and P. eurygaster) (Tanaka and Takefushi 1993), and the potential for feeding on louse eggs may motivate grooming behavior (Onishi et al. 2013). Japanese macaques also remove ticks, e.g., Haemaphysalis longicornis, during grooming (Tanaka and Takefushi 1993; Zamma 2002a), but this is rarely observed and the number of ticks on Japanese macaques is much smaller than that of lice (Zamma 2002a).

As in other primates, e.g., pigtail macaques (Macaca nemestrina) and bonnet macaques (Macaca radiate: Defler 1978), baboons (Young et al. 1982), red howlers (Sánchez-Villagra et al. 1998), Japanese macaques exhibit sex- and age-dependent differences in grooming behavior. Females groom other individuals significantly more frequently than males from about 28 weeks of age, and females continue to increase their rate of grooming until age 1 yr. (Eaton et al. 1985). Moreover, grooming between unrelated macaques occurs mainly among females (Ando 1982). Mothers preferentially groom their youngest offspring (Koyama 1977) and adolescent males spend slightly more time self-grooming than other age-sex classes (Maruhashi 1981). Changes in technique for effectively removing louse eggs are related to the ontogenetic growth of incisors (Tanaka and Takefushi 1993). Two types of louse egg handling techniques have been reported in Japanese macaques: removal using the lower incisors and removal using the first finger and thumb (Tanaka and Takefushi 1993). Although juveniles with lacteal incisors appear to be able to remove lice eggs accurately, egg removal becomes less accurate when the permanent incisors erupt. In contrast, adult macaques appear to use mainly their first fingers and thumbs to remove louse eggs (Tanaka and Takefushi 1993). Additionally, behavioral data indirectly suggest that lice load on Japanese macaques is higher in summer and fall than in spring and winter (Duboscq et al. 2016). The authors suggested that seasonal change of louse habitat caused by seasonal fluctuations in hormones and seasonal changes of hair density and length of host macaques may cause seasonal differences of lice load (Duboscq et al. 2016).

We examined sex-, age-, and season-related differences in the number of louse eggs on the fur of free-ranging Japanese macaques. We took advantage of a planned cull of Japanese macaques to measure the number of louse eggs on different individuals. Lice spend their entire lifecycle on their host (Wall and Shearer 2001) and female lice glue their eggs onto the hair shafts of their mammalian hosts (Durden 2001), meaning that we can count louse eggs on dead host macaques because they are attached to the hair (Tanaka and Takefushi 1993). Based on known variation in grooming behavior among Japanese macaques as well as known seasonal differences in hair density, we hypothesized that the number of louse eggs found on fur, i.e., those that were not removed by grooming, depends on the sex and age of the host and season. We tested three predictions: 1) females that are groomed more frequently by other individuals than are males have fewer eggs than males do; 2) age classes differ in the number of eggs, owing to differences in the amount of grooming they receive; 3 ) the number of louse eggs differs between individuals that have a winter coat and those that have a summer coat. 


\section{Methods}

\section{Data Collection}

We counted the number of louse eggs on the carcasses of 64 wild Japanese macaques inhabiting Fukushima City, Fukushima Prefecture, Japan. At the request of Fukushima City, licensed hunters culled macaques from June 2009 to July 2011. The Fukushima Mirai Agricultural Cooperative froze macaque carcasses in Fukushima City, and we then transported the frozen carcasses to the Nippon Veterinary and Life Science University, where we defrosted carcasses at room temperature for 2 days to 1 week. We adjusted the defrosting period depending on the season to avoid putrefaction of the carcasses. After defrosting, we dissected the carcasses and collected skin samples.

The number of louse eggs varies between body parts, and many louse eggs are found on the arm (Zamma 2002a), where it is relatively easy to collect skin samples. Moreover, louse eggs are more often found on the outer side of the body than on its inner side (Zamma 2002a). To avoid bias in louse egg counts, we obtained all skin samples from within $5 \mathrm{~cm}$ from the root of the left wrist of each macaque, and scanned both the inner and outer side isometrically.

During necropsy, we determined the sex and estimated the age of each macaque using tooth eruption status in accordance with Iwamoto et al. (1987). We divided individuals into the following groups based on estimated age: infant $(<1.5 \mathrm{yr})$, juvenile (1.5-3.5 yr), adolescent (3.5-5.5 yr), and adult ( $\geq 5.5 \mathrm{yr}$ ). We also noted whether or not juvenile macaques had adult incisors. After necropsy and sampling skin, we froze all samples for processing at a later date.

To assess seasonal differences in the number of louse eggs, we categorized individuals into those with a winter coat (culled between October and March) and those with a summer coat (culled between April and September) following the methods of Inagaki and Nigi (1988). We sampled five winter coats and three summer coats for each age-sex class (Table I).

We defrosted skin samples at room temperature and counted the number of louse eggs. We randomly selected three $1-\mathrm{cm}^{2}$ areas of skin from both the outer and inner side of the left wrist. In total, we sampled six areas for each macaque. We examined hairs on each of the six areas using a stereomicroscope (Shimazu STZ-40TBITb, Tokyo, Japan). If objects were attached to the hair, we cut the hair at the root, fixed it, and stored it in acetone. The same person processed all skin samples and extracted all objects.

\section{Data Analysis}

We assigned objects collected from skin samples to one of three categories: unhatched eggs, hatched eggs, or other objects. Two observers sorted all objects using a stereoscopic microscope to reduce any bias in the sorting of small objects. The degree of concordance between the results of the two observers was high $(\kappa=0.86)$. We therefore used the results from just one observer for statistical tests.

We used a univariate negative binomial regression analysis for each variable to assess the associations of sex, season, and age of monkeys with the total counts of unhatched and hatched eggs remaining on hair shafts close to the host skin on all skin patches for each individual. We then used post hoc pairwise comparisons to compare 
Table I Sample size of Japanese macaques at Fukushima City, Fukushima Prefecture, Japan, by age, sex, and season (June 2009July 2011)

${ }^{\mathrm{a}} 11$ of 16 individuals had permanent incisors, and the other 5 individuals had lacteal incisors only

\begin{tabular}{|c|c|c|c|}
\hline Age & Sex & Season & $N$ \\
\hline \multirow[t]{4}{*}{ Infant } & Male & Winter & 5 \\
\hline & & Summer & 3 \\
\hline & Female & Winter & 5 \\
\hline & & Summer & 3 \\
\hline \multirow[t]{4}{*}{ Juvenile $^{\mathrm{a}}$} & Male & Winter & 5 \\
\hline & & Summer & 3 \\
\hline & Female & Winter & 5 \\
\hline & & Summer & 3 \\
\hline \multirow[t]{4}{*}{ Adolescent } & Male & Winter & 5 \\
\hline & & Summer & 3 \\
\hline & Female & Winter & 5 \\
\hline & & Summer & 3 \\
\hline \multirow[t]{4}{*}{ Adult } & Male & Winter & 5 \\
\hline & & Summer & 3 \\
\hline & Female & Winter & 5 \\
\hline & & Summer & 3 \\
\hline
\end{tabular}

age classes with Bonferroni adjustment for multiple comparisons after univariate negative binomial regression analysis for unhatched and hatched eggs. We used Stata/IC 13.1 (StataCorp LP, College Station, TX, USA) for analysis.

We used Student's $t$-tests in R. 3.2.3 (R Core Team 2015) to test the difference in numbers of unhatched and hatched eggs between juveniles with lacteal incisors and those with permanent incisors.

\section{Ethical Note}

Licensed hunters set box traps and shot all macaques used in this study at the request of Fukushima City between June 2009 and September 2011 as a measure against crop damage. Fukushima Prefecture made both the decision to cull animals and the decision of which animals to cull independently of this study. We did not influence these decisions. Licensed hunters captured and killed monkeys with the permission of the governor of Fukushima Prefecture, Japan, according to the Fukushima Japanese Monkey Management Plan, which was established based on the Wildlife Protection and Hunting Management Law of Japan. The method of culling was in accordance with the guidelines published by the Primate Research Institute, Kyoto University.

\section{Results}

In total, we detected 2036 objects in samples from 45 of the 64 macaques, and no objects on the remaining 19 individuals. We counted 294 unhatched eggs, 1631 hatched eggs, and 111 other objects. 
Age had an effect on the number of the unhatched and hatched eggs, but sex and season had no effect on the number of the unhatched and hatched eggs (Tables II and III). Pairwise comparisons showed that the number of unhatched eggs differed significantly between infants and adults, juveniles and adults, and adolescents and adults (Table III, Fig. 1). The number of hatched eggs differed significantly between infants and adults, juveniles and adults, and adolescents and adults (Table III, Fig. 1).

The mean numbers of unhatched and hatched eggs did not differ between juvenile macaques that had lacteal incisors and those with permanent incisors ( $t$-test: unhatched eggs, $t=1.17$, df $=14, P=0.26$; hatched eggs, $t=1.08, \mathrm{df}=14, P=0.30$ ).

\section{Discussion}

Our results indicate that the number of louse eggs on hair shafts close to the skin varies significantly among macaque age groups, but not by sex and season. There was a significant difference in unhatched eggs between infants and adults, juveniles and adults, and adolescents and adults. There was also a significant difference in hatched eggs between infants and adults, juveniles and adults, and adolescents and adults. Juveniles harbored more hatched and unhatched eggs than other age classes, but there was no significant difference in unhatched and hatched eggs between juveniles and adolescents. This may be due to one adolescent macaque that had 27 unhatched eggs and 234 hatched eggs, while all other adolescents had fewer than 15 unhatched eggs and fewer than 30 hatched eggs. It is unclear why this individual was such an outlier. There were no significant differences in the numbers of unhatched or hatched eggs between juvenile macaques with lacteal vs. permanent incisors. The number of louse eggs found on macaques might relate to factors such as grooming rates, hair density,

Table II Results of univariate negative binomial regression analysis testing for factors associated with the number of unhatched and hatched eggs on Japanese monkeys at Fukushima City, Fukushima Prefecture, Japan (June 2009-July 2011)

\begin{tabular}{llllll}
\hline & & & Coefficient & 95\% CI & $P$-value \\
\hline Unhatched eggs & Sex $(N=64)$ & & 0.16 & -8.70 to 1.20 & 0.757 \\
& Season $(N=64)$ & & -0.85 & -1.90 to 0.19 & 0.108 \\
& Age & Infant $(N=16)$ & Reference & & \\
& & Juvenile $(N=16)$ & 1.20 & 0.06 to 2.35 \\
Hatched eggs & Adolescent $(N=16)$ & 0.07 & -1.10 to 1.24 \\
& Sex $(N=64)$ & Adult $(N=16)$ & -3.30 & -5.09 to -1.50 \\
& Season $(N=64)$ & & -0.15 & -1.22 to 0.93 & 0.786 \\
& Age & Infant $(N=16)$ & Reference & -0.94 to 1.28 & 0.767 \\
& & Juvenile $(N=16)$ & 1.11 & -0.04 to 2.26 \\
& Adolescent $(N=16)$ & 0.02 & -1.13 to 1.18 \\
& Adult $(N=16)$ & -4.68 & -6.29 to -3.07
\end{tabular}


Table III Results for pairwise comparison with Bonferroni adjustment of hatched and unhatched eggs between each age group on Japanese monkeys at Fukushima City, Fukushima Prefecture, Japan (June 2009July 2011)

\begin{tabular}{lllllllll}
\hline & Age & & Contrast & Standard error & $Z$ & $P>|Z|$ & $95 \%$ Cl \\
\hline Unhatched egg & Infant & Juvenile & 1.20 & 0.59 & 2.06 & 0.239 & 0.56 to 2.35 \\
& & Adolescent & 0.07 & 0.60 & 0.12 & 1.000 & -1.10 to 1.24 \\
& & Adult & -3.30 & 0.92 & -3.60 & 0.002 & -5.09 to -1.50 \\
& \multirow{4}{*}{ Juvenile } & Adolescent & -1.13 & 0.58 & -1.94 & 0.316 & -2.28 to 0.01 \\
& & Adult & -4.50 & 0.91 & -4.96 & $<0.001$ & -6.28 to -2.72 \\
& \multirow{4}{*}{ Hatched egg } & Adolescent & Adult & -3.37 & 0.91 & -3.68 & 0.001 & -5.16 to -1.58 \\
& Infant & Juvenile & -5.28 & 0.98 & 1.89 & 0.349 & -0.04 to 2.26 \\
& & Adolescent & -6.26 & 1.04 & 0.04 & 1.000 & -1.13 to 1.18 \\
& & Adult & -7.24 & 1.10 & -5.69 & $<0.001$ & -6.29 to -3.07 \\
& \multirow{4}{*}{ Juvenile } & Adolescent & -8.23 & 1.17 & -1.85 & 0.384 & -2.23 to 0.06 \\
& & Adult & -9.21 & 1.23 & -7.05 & $<0.001$ & -7.39 to -4.18 \\
& \multirow{2}{*}{ Adolescent } & Adult & -10.19 & 1.30 & -5.72 & $<0.001$ & -6.31 to -3.09 \\
& & & & & & & \\
\hline
\end{tabular}

and hormone levels. Moreover, host immunity and habitat might also influence the number of eggs. However, our results are generally consistent with those of previous studies where the number of unhatched and hatched eggs seemed to be affected by grooming (Duboscq et al. 2016; Zamma 2002a), and it is possible to explain some of the variability across age groups using known patterns of grooming behavior.

Grooming partners of Japanese macaques are nonrandom, and more than half of grooming occurs between relatives (Ando 1982; Koyama 1991; Nakamichi and Shizawa 2003; Oki and Maeda 1974). In particular, about $70 \%$ of all grooming between relatives occurs between mothers and their offspring (Ando 1982; Koyama 1991). However, the relationship between mothers and their offspring depends on the number of offspring, with the amount of grooming each offspring receives from the mother being negatively related to offspring number and the youngest offspring receiving more than a third of all mother-offspring grooming (Koyama 1977). The mean pregnancy rate among wild Japanese macaques aged $\geq 4$ yr. living in Fukushima City was estimated to be $49 \%$ (Hayama et al. 2011), with females of reproductive age giving birth once every other year. Juveniles between 1.5 to $3.5 \mathrm{yr}$. old are likely therefore to have a younger sibling, with this younger sibling receiving more grooming from their mothers than they do. This difference in rates of maternal grooming may partly explain the observed difference in the number of louse eggs between infants and juveniles. Maternal grooming might be particularly important in preventing lice-borne infections in infants, since serum immunoglobulin content gradually rises with increasing age, up to sexual maturity (cynomolgus monkeys: Terao 2009).

Juveniles may struggle to remove louse eggs by themselves. Although we hypothesized that the number of louse eggs might differ between juveniles with lacteal vs. permanent incisors, we found no significant differences in the numbers of unhatched and hatched eggs between these two groups. Together with the high numbers of louse eggs on juveniles, this suggests that juvenile macaques may not be able to remove louse eggs accurately, irrespective of the grooming method used. 

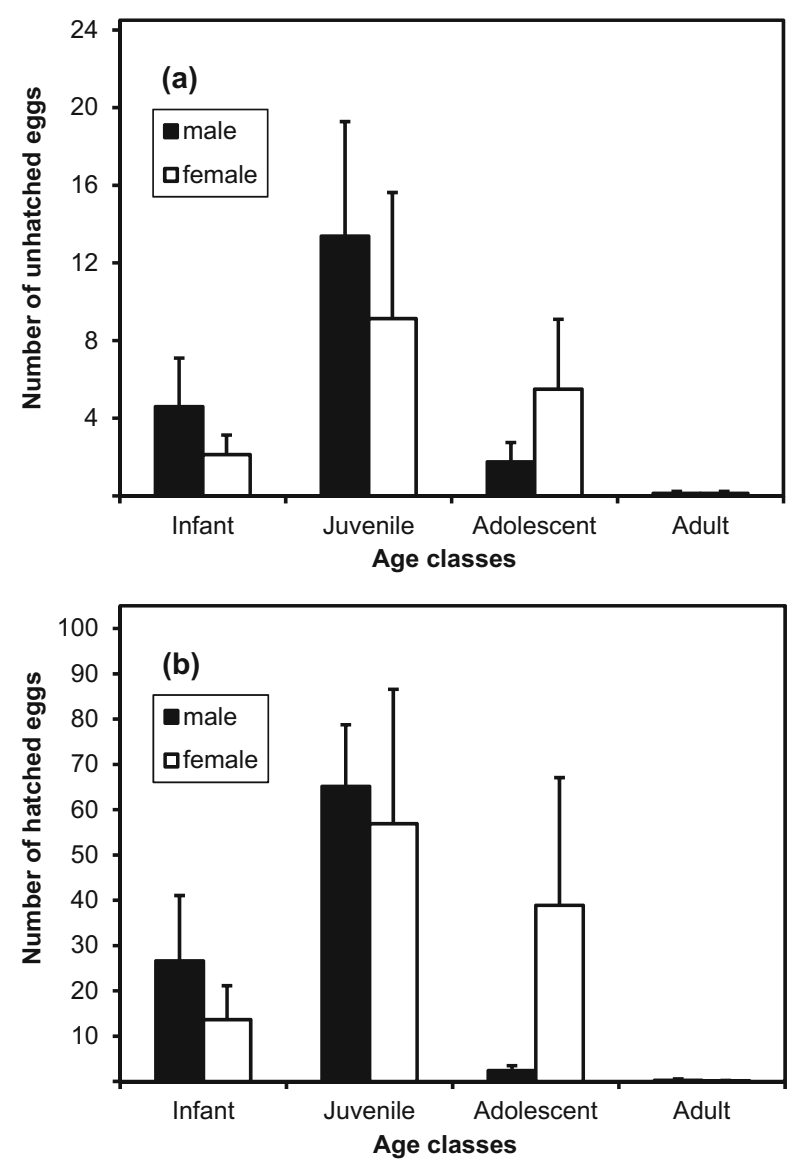

Fig. 1 Mean and standard error of the number of (a) unhatched and (b) hatched eggs for each sex and age class of Japanese macaques at Fukushima City, Fukushima Prefecture, Japan (June 2009-July 2011)

Although the number of lice living on the macaques is unclear because we did not count live adult lice, the observation that $>80 \%$ of the 1925 louse eggs detected were hatched suggests that adult lice would have been present on the macaques before death. Zamma (2002a) suggests that it is difficult for monkeys to remove all lice by hand, and that both lice and louse eggs are expected to maintain a certain population level. We can infer that juvenile macaques, with the most hatched eggs, are parasitized by many adult lice. Lice pass from host to host most efficiently when "bridges" between hairs exist (Bowman 2009). Given that social play with direct contact in Japanese macaques occurs between individuals whose age disparity is <3 yr. (Imakawa 1990; Koyama 1985; Mori 1974), contact between juveniles is likely to be high, leading to cross-infections.

Sex- and/ or season-related differences have been reported in some cases of Phthiraptera infestation (Durden 2001; James et al. 1998; Murray 1963; Rassami and Soonwera 2012; Volf 1991); however, our results did not indicate sex- and season-related differences in the number of lice eggs on Japanese macaques. Lice load calculated indirectly by data on louse egg-picking gestures is higher in the summer and fall compared to the spring and winter (Duboscq et al. 2016). Our direct count data that 
found no seasonal difference in the number of louse eggs may reflect egg removal during grooming, which suggests prevention of season-related and potentially sexrelated differences in infestation by grooming. However, we cannot definitively support this suggestion for two reasons. First, whereas Duboscq et al. (2016) divided the year into four seasons, in the present study we used just two seasons, which may mask changes in lice egg number over the year. Second, it is unclear whether the absence of sex differences is related to differences in removal behavior, or whether there were simply no sex differences to begin with. Further examination is needed to test our hypothesis, for example, using a combination of behavioral observations and direct counts of louse eggs.

We did not measure grooming behavior directly in this study, and behavioral studies are needed to conclude that grooming patterns are linked to age-related infection differences. Other potential causes include differences in hair density (Zamma 2002a). The density of Japanese macaque hair is not dependent on sex (Inagaki and Hamada 1985), but decreases during development (Inagaki 1992). A higher hair density on juveniles than on adults could explain the greater number of louse eggs observed in juveniles in our study, consistent with the results of Zamma (2002a). However, infants have even higher hair density than juveniles, yet appear to have fewer louse eggs, such that hair density alone cannot explain the observed differences in the number of louse eggs across the different age groups. Higher maternal grooming rates of infants may interact with hair density differences to create the observed patterns.

Host immunity may also play a role in lice infestation. In tick infestations, basophils play an essential and nonredundant role in antibody-mediated acquired immunity (Wada et al. 2010). Moreover, when a host acquires resistance against ticks, feeding by ticks is reduced (Wada et al. 2010). There are no studies to our knowledge that report how the Japanese macaque's immune system reacts to lice. However, Durden (2001) suggested that systemic immunity to lice can probably develop in parasitized mammals, and that cellular responses presumably operate in wild mammals. Based on the host response to ticks (Wada et al. 2010), it is possible that louse infestations also cause immune reactions, and the number of lice and louse eggs may be higher on individuals that do not have fully functioning immune systems and cannot prevent pediculosis.

Finally, differences in environmental temperature may affect the number of louse eggs. Japanese macaques huddle in groups, and the size of these groups increases as the temperature drops, creating greater potential for interindividual transmission (Hanya et al. 2007; Takahashi 1997; Wada et al. 2007; Zhang and Watanabe 2007). Hair density is also related to temperature; macaques that live in cold regions have a higher hair density than macaques in warm areas, and may also have higher numbers of louse eggs (Inagaki 1992).

In conclusion, our results show that the number of louse eggs differs across individuals and with host age. Sex and/or age have not been a focus of many previous studies of the relationship between grooming and ectoparasites, but a difference in louse burden with host age may lead to differences in health. Researchers should examine primate grooming data, ectoparasite count data, and primate health data to test this hypothesis (as in Akinyi et al. 2013). Grooming in primates may have a social function (Boccia et al. 1989; Dunbar 1991; Schino et al. 1988) and/or a hygienic function (Barton 1985; Hutchins and Barash 1976; Reichard and Sommer 1994). There is evidence of decreased heart rate (Aureli et al. 1999; Boccia et al., 1989) and stress biomarkers (Shutt et al. 2007) and improved psychological well-being (Keverne et al. 
1989) in relation to grooming. However, to our knowledge, only one report shows direct evidence for the hygienic function of primate grooming (Akinyi et al. 2013). Future studies should clarify the health benefits of ectoparasite removal, to further our understanding of the function of grooming.

Data Availability Statement The datasets analyzed during the current study are available from the corresponding author on reasonable request.

Acknowledgments This study was made possible by the cooperation of Fukushima City. We thank all members involved in this study, especially Mr. Fumiharu Konno. We also thank Ms. Sachie Nakiri and all members who helped collect skin samples. We are grateful to editor-in-chief Joanna M. Setchell, associate editor James Higham, and the two anonymous reviewers for their useful and insightful comments on the manuscript.

\section{Compliance with ethical standards}

Conflict of interest The authors declare that they have no conflict of interest.

Open Access This article is distributed under the terms of the Creative Commons Attribution 4.0 International License (http://creativecommons.org/licenses/by/4.0/), which permits unrestricted use, distribution, and reproduction in any medium, provided you give appropriate credit to the original author(s) and the source, provide a link to the Creative Commons license, and indicate if changes were made.

\section{References}

Akinyi, M. Y., Tung, J., Jeneby, M., Patel, N. B., Althmann, J., \& Alberts, S. C. (2013). Role of grooming in reducing tick load in wild baboons (Papio cynocephalus). Animal Behaviour, 85, 559-568.

Ando, A. (1982). Analysis of grooming relationships in a free-ranging group of Japanese macaques (Macaca fuscata). The Annual of Animal Psychology, 32, 59-71 (In Japanese with English abstract).

Aureli, F., Preston, S. D., \& de Waal, F. B. M. (1999). Heart rate responses to social interactions in free-moving rhesus macaques (Macaca mulatta): A pilot study. Journal of Comparative Psychology, 133, 59-65.

Barton, R. (1985). Grooming site preferences in primates and their functional implications. International Journal of Primatology, 6, 519-532.

Blanc, G., \& Woodward, T. E. (1945). The infection of Pedicinus albidus Rudow the maggot's louse on typhus carrying monkeys (Macacus sylvanus). The American Journal of Tropical Medicine and Hygiene, $25,33-34$.

Boccia, M. L., Reite, M., \& Laudenslager, M. (1989). On the physiology of grooming in a pigtail macaque. Physiology \& Behavior, 45, 667-670.

Borges, R., \& Mendes, J. (2002). Epidemiological aspects of head lice in children attending day care centres, urban and rural schools in Uberlandia, central Brazil. Memórias do Instituto Oswaldo Cruz, 97, 189-192.

Bowman, D. D. (2009). Arthropods. In G. Jolynn (Ed.), Georgis' parasitology for veterinarians (9th ed., pp. 5-83). St. Louis: W. B. Saunders.

Burgess, I. F. (1995). Human lice and their management. Advances in Parasitology, 36, 271-324.

Cote, I. M. (2000). Evolution and ecology of cleaning symbioses in the sea. Oceanography and Marine Biology, 38, 311-355.

Defler, T. R. (1978). Allogrooming in two species of macaque (Macaca nemestrina and Macaca radiata). Primates, 19, 153-167.

Duboscq, J., Romano, V., Sueur, C., \& MacIntosh, A. J. (2016). Network centrality and seasonality interact to predict lice load in a social primate. Scientific Reports, 6, 22095.

Dunbar, R. I. M. (1991). Functional significance of social grooming in primates. Folia Primatologica, 57, 121-131.

Durden, L. A. (2001). Lice (Phtiraptera). In W. M. Samuel, M. J. Pybus, \& A. A. Kocan (Eds.), Parasitic diseases of wild mammals (2nd ed., pp. 3-17). Ames: Iowa State University Press.

Eaton, G. G., Johnson, D. F., Glick, B. B., \& Worlein, J. M. (1985). Development in Japanese macaques (Macaca fuscata): Sexually dimorphic behavior during the first year of life. Primates, 26, 238-247. 
Eckstein, R. A., \& Hart, B. L. (2000). Grooming and control of fleas in cats. Applied Animal Behaviour Science, 68, 141-150.

Foster, M. S. (1969). Synchronized life cycles in the orange-crowned warbler and its mallophagan parasites. Ecology, 50, 315-323.

Guss, D. A., Koenig, M., \& Castillo, E. M. (2011). Severe iron deficiency anemia and lice infestation. The Journal of Emergency Medicine, 41, 362-365.

Hanya, G., Kiyono, M., \& Hayaishi, S. (2007). Behavioral thermoregulation of wild Japanese macaques: Comparisons between two subpopulations. American Journal of Primatology, 69, 802-815.

Hart, B. L. (2000). Role of grooming in biological control of ticks. Annals of the New York Academy of Sciences, 916, 565-569.

Hayama, S., Nakiri, S., \& Konno, F. (2011). Pregnancy rate and conception date in a wild population of Japanese monkeys. Journal of Veterinary Medical Science, 73, 809-812.

Hutchins, M., \& Barash, D. P. (1976). Grooming in primates: Implications for its utilitarian function. Primates, $17,145-150$.

Imakawa, S. (1990). Playmate relationships of immature free-ranging Japanese monkeys at Katsuyama. Primates, 31, 509-521.

Inagaki, H. (1992). Geographical variation of hairs of the Japanese monkey (Macaca fuscata). Primate Research, 8, 49-67 (In Japanese with English abstract).

Inagaki, H., \& Hamada, Y. (1985). Differences in hair density of Japanese monkeys (Macaca fuscata fuscata) with locality and age. Primates, 26, 85-90.

Inagaki, H., \& Nigi, H. (1988). Annual changes in hair length of the Japanese monkey (Macaca fuscata fuscata). Primates, 29, 81-89.

Iwamoto, M., Watanabe, T., \& Hamada, Y. (1987). Eruption of permanent teeth in Japanese monkeys (Macaca fuscata). Primate Research, 3, 18-28 (In Japanese with English abstract).

James, P. J., Moon, R. D., \& Brown, D. R. (1998). Seasonal dynamics and variation among sheep in densities of the sheep biting louse, Bovicola ovis. International Journal for Parasitology, 28, 283-292.

Johnson, P. T., Dobson, A., Lafferty, K. D., Marcogliese, D. J., Memmott, J., et al (2010). When parasites become prey: Ecological and epidemiological significance of eating parasites. Trends in Ecology \& Evolution, 25, 362-371.

Keverne, E. B., Martensz, N. D., \& Tuite, B. (1989). Beta-endorphin concentrations in cerebrospinal fluid of monkeys are influenced by grooming relationships. Psychoneuroendocrinology, 14, 155-161.

Kjemtrup, A. M., \& Conrad, P. A. (2000). Human babesiosis: An emerging tick-borne disease. International Journal for Parasitology, 30, 1323-1337.

Koyama, N. (1977). The social structure of Japanese monkeys. In J. Itani (Ed.), Anthropology, Vol. 2: Primates (pp. 225-276). Tokyo: Yuzankaku Press. (In Japanese)

Koyama, N. (1985). Playmate relationships among individuals of the Japanese monkey troop in arashiyama. Primates, 26, 390-406.

Koyama, N. (1991). Grooming relationships in the Arashiyama group of Japanese monkeys. In L. M. Fedigan \& P. J. Asquith (Eds.), The monkeys of Arashiyama: Thirty-five years of research in Japan and the West (pp. 221-226). Albany: State University of New York Press.

Kutsukake, N., \& Clutton-Brock, T. H. (2006). Aggression and submission reflect reproductive conflict between females in cooperatively breeding meerkats Suricata suricatta. Behavioral Ecology and Sociobiology, 59, 541-548.

Maruhashi, T. (1981). Activity patterns of a troop of Japanese monkeys (Macaca fuscata yakui) on Yakushima Island, Japan. Primates, 22, 1-14.

Minami, T. (1987). Behavioral development and sex differences in primates. Osaka University Knowledge Archive, 13, 269-298 (In Japanese with English abstract).

Mitchell, G., \& Tokunaga, D. H. (1976). Sex differences in nonhuman primate grooming. Behavioural Processes, 1, 335-345.

Mori, U. (1974). The inter-individual relationships observed in social play of the young Japanese monkeys of the natural troop in Koshima Islet. Journal of the Anthropological Society of Nippon, 82, 303-318 (In Japanese with English abstract).

Murray, D. R. (1963). The ecology of lice on sheep. IV. The establishment and maintenance of populations of Linognathus ovillus (Neumann). Australian Journal of Zoology, 11, 157-172.

Nakamichi, M., \& Shizawa, Y. (2003). Distribution of grooming among adult females in a large, free-ranging group of Japanese macaques. International Journal of Primatology, 24, 607-625.

Nozaki, M. (1991). Mechanisms controlling seasonal breeding in Japanese monkeys. Primate Research, 7 , 103-125 (In Japanese with English abstract). 
Oki, J., \& Maeda, Y. (1974). Grooming behavior as a regulator of behavior in Japanese macaques. In C. R. Carpenter (Ed.), Behavioral regulators of behavior in primates (pp. 140-164). Lewisburg: Bucknell University Press.

Onishi, K., Yamada, K., \& Nakamichi, M. (2013). Grooming-related feeding motivates macaques to groom and affects grooming reciprocity and episode duration in Japanese macaques (Macaca fuscata). Behavioural Processes, 92, 125-130.

Peng, Y. S., Fang, Y., Xu, S., \& Ge, L. (1987). The resistance mechanism of the Asian honey bee, Apis cerana Fabr., to an ectoparasitic mite, Varroa jacobsoni Oudemans. Journal of Invertebrate Pathology, 49, 54-60.

Rassami, W., \& Soonwera, M. (2012). Epidemiology of pediculosis capitis among schoolchildren in the eastern area of Bangkok, Thailand. Asian Pacific Journal of Tropical Biomedicine, 2, 901-904.

Reichard, U., \& Sommer, V. (1994). Grooming site preferences in wild white-handed gibbons (Hylobates lar). Primates, 35, 369-374.

R Core Team (2015). R: A language and environment for statistical computing. Vienna, Austria: R Foundation for Statistical Computing https://www.R-project.org/.

Ronald, N. C., \& Wagner, J. F. (1973). Pediculosis of spider monkeys: A case report with zoonotic implications. Laboratory Animal Science, 23, 872-875.

Roux, V., \& Raoult, D. (1999). Body lice as tools for diagnosis and surveillance of reemerging diseases. Journal of Clinical Microbiology, 1999, 596-599.

Ruebush 2nd, T. K., Piesman, J., Collins, W. E., Spielman, A., \& Warren, M. (1981). Tick transmission of Babesia microti to rhesus monkeys (Macaca mulatta). The American Journal of Tropical Medicine and Hygiene, 30, 555-559.

Sánchez-Villagra, M. R., Pope, T. R., \& Salas, V. (1998). Relation of intergroup variation in allogrooming to group social structure and ectoparasite loads in red howlers (Alouatta seniculus). International Journal of Primatology, 19, 473-491.

Schino, G., Scucchi, S., Maestripieri, D., \& Turillazzi, P. G. (1988). Allogrooming as a tension-reduction mechanism: A behavioral approach. American Journal of Primatology, 16, 43-50.

Shutt, K., Mac Larnon, A., Heistermann, M., \& Semple, S. (2007). Grooming in Barbary macaques: Better to give than to receive? Biology Letters, 3, 231-233.

Sparks, J. (1967). Allogrooming in primates: A review. In M. Desmond (Ed.), Primate ethology (pp. 148175). London: Weidenfeld \& Nicolson.

Speare, R., \& Buettner, P. G. (1999). Head lice in pupils of a primary school in Australia and implications for control. International Journal of Dermatology, 38, 285-290.

Speare, R., Canyon, D. V., \& Merrose, W. (2006). Quantification of blood intake of the head louse: Pediculus humanus capitis. International Journal of Dermatology, 45, 543-546.

Takahashi, H. (1997). Huddling relationships in night sleeping groups among wild Japanese macaques in Kinkazan Island during winter. Primates, 38, 57-68.

Tanaka, I., \& Takefushi, H. (1993). Elimination of external parasites (lice) is the primary function of grooming in free-ranging Japanese macaques. Anthropological Science, 101, 187-193.

Terao, K. (2009). Essentials for starting a pediatric clinical study (3): Dynamic changes in early development of immune system in macaque monkeys - The significance from standpoint of preclinical toxicity test using nonhuman primates. The Journal of Toxicological Sciences, 34(Special Issue 2), SP321-SP325.

Volf, P. (1991). Polyplax spinulosa infestation and antibody response in various strains of laboratory rats. Folia Parasitologica, 38, 355-362.

Wada, K., Tokida, E., \& Ogawa, H. (2007). The influence of snowfall, temperature and social relationships on sleeping clusters of Japanese monkeys during winter in Shiga Heights. Primates, 48, 130-139.

Wada, T., Ishiwata, K., Koseki, H., Ishikura, T., Ugajin, T., et al (2010). Selective ablation of basophils in mice reveals their nonredundant role in acquired immunity against ticks. The Journal of Clinical Investigation, 120, 2867-2875.

Wall, R., \& Shearer, D. (2001). Lice (Phthiraotera). In R. Wall \& D. Shearer (Eds.), Veterinary ectoparasites: Biology, pathology and control (2nd ed., pp. 162-178). Oxford: Blackwell Science.

Young, G. H., Coelho Jr., A. M., \& Bramblett, C. A. (1982). The development of grooming, sociosexual behavior, play and aggression in captive baboons in their first two years. Primates, 23, 511-519.

Zamma, K. (2002a). Grooming site preferences determined by lice infection among Japanese macaques in Arashiyama. Primates, 43, 41-49.

Zamma, K. (2002b). Leaf-grooming by a wild chimpanzee in Mahale. Primates, 43, 87-90.

Zhang, P., \& Watanabe, K. (2007). Extra-large cluster formation by Japanese macaques (Macaca fuscata) on Shodoshima Island, central Japan, and related factors. American Journal of Primatology, 69, 1119-1130. 